\section{Patogênese Molecular do Feocromocitoma}

\section{RESUMO}

Feocromocitoma é um tumor raro originário de células neuroectodérmicas. Em aproximadamente $10 \%$ dos casos, estes tumores são herdados. Existem múltiplas formas familiares de feocromocitomas, entre as quais a neoplasia endócrina do tipo 2, a síndrome de von Hippel Lindau, a neurofibromatose tipo 1, formas familiares isoladas de feocromocitoma e possivelmente outros subtipos menos bem caracterizados. Ao mesmo tempo em que se tem observado nos últimos anos um importante avanço quanto à definição do defeito genético responsável pela maior parte das síndromes hereditárias associadas ao feocromocitoma, houve pouco progresso na caracterização da patogênese molecular das variantes esporádicas destes tumores, assim como em grande parte das formas familiares isoladas. Esta revisão apresenta um resumo dos aspectos moleculares das diversas formas de feocromocitomas familiares e esporádicos e finaliza com a proposição de estudos futuros que possam contribuir para elucidar alguns dos muitos aspectos da gênese deste tumor que ainda permanecem obscuros. (Arq Bras Endocrinol Metab 2001;45/6:507-519)

Unitermos: Feocromocitoma; Genética; Neoplasia; Esporádico; Mutação; Gene RET; Gene VHL; Gene SDHD.

\begin{abstract}
Pheochromocytomas are rare tumors arising from neuroectodermal cells. In $10 \%$ of the cases, these tumors can be inherited as part of multiple endocrine neoplasia type 2, von-Hippel Lindau syndrome, neurofibromatosis type 1, isolated forms of familial pheochromocytoma and other, less well characterized variants. While vast progress has been made in recent years towards the identification of the primary genetic defect leading to the major familial pheochromocytoma syndromes, characterization of the molecular events involved in determining the sporadic phenotype has lagged far behind. This review attempts to show a summary of the current molecular knowledge of the familial forms of pheochromocytoma as well as sporadic tumors. We conclude by proposing novel strategies aimed at shedding light into some aspects of pheochromocytoma pathogenesis that are yet to be elucidated. (Arq Bras Endocrinol Metab 2001;45/6:507-519)
\end{abstract}

Keywords: Pheochromocytoma; Neoplasia; Genetics; Mutation; Sporadic cancer; RET; VHL; SDHD.

$\mathbf{F}$ EOCROMOCITOMA É UM TUMOR RARO originário de células neuroectodérmicas que usualmente se localiza na medula adrenal ou, em uma percentagem menor (aproximadamente 10\%) dos casos, em tecido cromafim presente em células de origem simpática extra-adrenal, circunstância na qual pode ser também denominado paraganglioma (1). Feocromocitomas são capazes de secretar catecolaminas, determinando, por conseguinte, sintomas característicos de estados hiper-adrenérgicos. Estes tumores podem ser malignos em cerca del0 a $12 \%$ dos casos, quando apresentam uma evolução agressiva e reduzidos índices de cura. Embora a maioria dos casos revisão

Patricia L.M. Dabia

\author{
Department of Cancer Biology, \\ Dana-Farber Cancer Institute, \\ Harvard Medical School, \\ Boston, MA, EUA.
}


de feocromocitoma seja esporádica, 10 a $15 \%$ podem ser hereditários. Pelo menos três (e provavelmente um número maior, à medida que dados mais recentes são incorporados na literatura) síndromes clínicas apresentam, de forma bem documentada, feocromocitoma como um dos seus componentes: a neoplasia endócrina múltipla do tipo 2 (NEM 2), a síndrome de von Hippel-Lindau e neurofibromatose tipo 1. Há, entretanto, evidência clínica e molecular da existência de outras variantes de feocromocitoma familiar, que serão comentadas em maiores detalhes ao final desta revisão.

Este artigo tratará de aspectos genéticos e moleculares da patogênese do feocromocitoma, com enfoque nas formas hereditárias. Características clínicas do feocromocitoma estão fora do escopo desta revisão. A esta seção inicial se seguirá um breve resumo do estado atual dos estudos realizados em tumores esporádicos. Por fim, faremos uma análise crítica dos futuros passos em relação a estratégias para a caracterização de alterações moleculares e propostas para atingir um melhor entendimento da base genética destes tumores.

É importante ressaltar que enquanto um relativo sucesso no avanço da genética molecular tem sido a regra em formas hereditárias de feocromocitoma - este paradigma, na verdade, se aplica a outros tipos de tumores sólidos - o mesmo progresso não foi visto em relação às variantes esporádicas $(2,3)$. Como mencionado acima, este tema vai ser discutido em uma seção específica desta revisão.

\section{FEOCROMOCITOMA NA NEOPLASIA ENDÓCRINA MÚLTIPLA TIPO 2}

Apesar de não ter sido o primeiro gene a ser identificado em associação com uma das formas de feocromocitoma hereditário (veja seção sobre o gene NFI, abaixo), o protooncogene RET pode ser considerado um dos mais extensamente estudados no aspecto genético. O RET foi caracterizado em 1993 como o gene responsável pela susceptibilidade à neoplasia múltipla tipo 2 (NEM 2) $(4,5)$. O termo NEM 2 abriga um conjunto de três síndromes, NEM 2A, NEM 2B e carcinoma medular de tiróide familiar (CMT-F), que possuem elementos clínicos comuns (6). As três síndromes se caracterizam pela presença de carcinoma medular de tiróide ou seu precursor, hiperplasia de células $\mathrm{C}$, sendo que no tipo $2 \mathrm{~A}$ a este quadro se associam feocromocitoma em cerca de $50 \%$ dos casos (comumente bilateral) e hiperparatiroidismo resultante de hiperplasia e adenoma de múltiplas paratiróides. No tipo $2 \mathrm{~B}$, feocromocitoma também é encontrado, assim como neurinomas mucosos do trato gastrointestinal, hábito marfanóide e alterações de desenvolvimento embrionário. Hiperparatiroidismo é virtualmente ausente nestes casos. CMT-F se caracteriza pela exclusiva presença de hiperplasia ou carcinoma de células $\mathrm{C}$ da tiróide em pelo menos dois indivíduos consangüíneos em primeiro grau, sem outros componentes clínicos.

\section{Aspectos funcionais da proteína RET}

O gene RET codifica um receptor com atividade tirosina quinase (7). Este grupo de proteínas se caracteriza por uma longa porção extracelular com uma região rica em cisteínas posicionadas a espaços regulares e que são críticas para a sua homodimerização. Além deste domínio extra-celular, o RET possui uma região transmembrana, e uma porção intracelular por meio da qual os sinais intracelulares são transmitidos. Ao contrário da maioria dos receptores que são ativados pelo acoplamento de um simples ligante, a ativação do RET se faz através de um complexo composto por uma molécula ligante, GDNF (fator neurotrófico derivado de células gliais (8)) e de um co-receptor ou molécula adaptadora, componente da família GFR $\alpha$ (receptor de GDNF do tipo $\alpha$ ) (9). Nenhuma das moléculas acima é capaz, individualmente, de ativar o receptor, de forma que há necessidade de formação do complexo trimérico RET/GRF/GDNF para que a ativação se processe e o sinal intracelular seja transmitido (10). Enquanto o GDNF é inteiramente solúvel, GFR $\alpha$ se encontra ancorado à superfície da membrana celular; porém, diferentemente de um receptor completo, este coreceptor não possui domínio intracelular, ação que é exercida neste contexto pelo RET. O receptor RET tem sido implicado em crescimento, diferenciação ou sobrevivência celular, funções que são resultantes da ativação de distintas vias sinalizadoras intracelulares. Estes sinais variam dependendo do tipo ou fase do desenvolvimento embrionário da célula-alvo. $\mathrm{O}$ resultado final desta ativação é determinado pelo tipo de proteína que se liga a um dos múltiplos resíduos tirosina, localizados na região intracelular do RET e, consequentemente, a via de sinalização ativada por tais proteínas, GRB7, GRB10, fosfolipase C- $\gamma$, SHC, GRB2, Src, Crk e Nck constituem alguns dos alvos de ativação do RET $(11,12)$. SHC e GRB2, por exemplo, são capazes de induzir transformação celular e mitogênese através da via RAS-MAPK, conhecida pelo seu envolvimento em uma série de neoplasias humanas (13); e também através da via fosfatidil inositol 3 quinase (PI3K) que, por sua vez, regula a proteína 
quinase $\mathrm{B}$ (PKB/AKT), resultando em aumento da sobrevivência celular e proliferação (14). É a atividade anormal e excessiva destas vias que resulta no fenótipo neoplásico visto neste grupo de doenças, embora, como será mencionado a seguir, o efeito de cada mutante do RET tenha um potencial de ativação distinto e possa se associar predominantemente a uma das vias de sinalização acima descritas.

Desde a sua identificação inicial, um vasto número de casos foi descrito com mutações do RET na linhagem germinativa (tabela 1 ). Iremos enfocar as mutações associadas com NEM $2 \mathrm{~A}$ e $2 \mathrm{~B}$, uma vez que estas duas variantes cursam com feocromocitoma. Atualmente, reconhece-se que mais de $98 \%$ dos casos de NEM 2A apresentam uma mutação do tipo missense, ou seja, que resulta em substituição do aminoácido original, afetando uma das cinco cisteínas correspondentes aos aminoácidos 609, 611, 618, 620 (exon $10)$ e 634 (exon 11) do RET $(15,16)$. A mutação mais freqüente, no códon 634 , ocorre em mais de $85 \%$ dos pacientes. O efeito biológico destas mutações é a perda do pareamento das cisteínas, que permite a formação de ligações intermoleculares resultando em dimerização e autofosforilação do RET independente de ação do ligante. Desta maneira, o receptor torna-se constitutivamente ativado (17).

As mutações que ocasionam NEM $2 \mathrm{~B}$ são menos variadas e mais específicas. Cerca de 98 a $99 \%$ dos pacientes com este subtipo de doença têm uma mutação identificada no códon 918, correspondente ao exon 16 (em 97\% dos casos, a metionina é substi-

Tabela 1. Correlação genotípica-fenotípica em NEM 2. Localização mais freqüente de mutações constitutivas do RET em subtipos de NEM 2.

\begin{tabular}{lcccc}
\hline Exons & Códons & CMT-F & NEM 2A & NEM 2B \\
\hline 10 & 609 & + & + & \\
& 611 & + & + & \\
& 618 & + & + & \\
& 620 & + & + & \\
11 & 630 & + & & \\
& 634 & + & + & \\
13 & 768 & + & & \\
& 790 & + & + & + \\
14 & 791 & + & & + \\
15 & 804 & + & & + \\
16 & 883 & & & \\
\hline
\end{tabular}

NEM 2 = neoplasia endócrina múltipla tipo 2; CMT-F carcinoma medular de tiróide. tuída por uma treonina) (18) ou no códon 883 (exon 15 , na qual a alanina se transforma em fenilalanina) (19). Ambas as mutações se localizam no domínio tirosina quinase do RET, e resultam em perda da especificidade aos seus substratos naturais (20). O receptor mutante passa a exercer funções compatíveis com quinases de localização citoplasmática, ao invés do seu papel como tirosina quinase do tipo receptor de superfície celular.

\section{Correlação Genótipo-Fenótipo em NEM 2}

Em vista desta vasta quantidade de informação gerada pela análise de mutações do RET em populações de várias origens étnicas afetadas por NEM 2, tem sido possível se delinear uma correlação genotípicafenotípica neste grupo de doenças (16,21). A associação genético-clínica mais importante nesta síndrome se observa na NEM 2B: todos os pacientes nos quais um defeito do RET é detectado possuem uma mutação do códon 918 ou 883. O reverso também é verdadeiro: estas mutações são exclusivamente detectadas no subtipo $2 \mathrm{~B}$, e nunca foram descritas nas outras formas de NEM 2. Contudo, embora nem todos os pacientes com NEM 2B apresentem feocromocitoma, este fato não determina qualquer variação em relação ao perfil genotípico da doença. Até o momento, a base para variação clínica entre famílias afetadas pela mesma mutação não está esclarecida. Portanto, é possível que estas mutações sejam necessárias mas não suficientes para o desenvolvimento de feocromocitomas, e outros fatores ainda não identificados podem contribuir para o aparecimento destes tumores em alguns casos de NEM 2B.

As correlações genótipo-fenótipo em NEM 2A e CMT-F são mais complexas, uma vez que uma maior variedade de mutações pode causar ambas as síndromes, além da existência de mutações idênticas encontradas nos dois subtipos $(21,22)$. Assim, o modelo corrente defende a existência de diferentes patamares de sensibilidade dos tecidos-alvo às diferentes formas mutantes do RET. Foi observado que a capacidade de expressão do RET na superfície celular varia substancialmente entre mutantes distintos $(23,24)$. A este fenômeno se atribui, ao menos em parte, as variações clínicas observadas. Assim, mutações do códon 634, típicas de NEM 2A, se associam à alta expressão de RET na superfície celular e aumentam a susceptibilidade para acometimento adrenal e de paratiróide (23). Em contraste com este quadro, mutações do códon 609, comuns em CMT-F, mas raramente vistas em NEM 2A, resultam em baixa expressão do RET na 
superfície (24). Como as células C da tiróide são o único tipo celular afetado nesta síndrome, acredita-se que estas células tenham maior sensibilidade para a transformação neoplásica induzida pelo RET mutado, de tal modo que não é necessário um alto nível de expressão do mutante na superfície da membrana para que a ativação anormal do sinal resulte em aumento da proliferação celular. Células da medula adrenal e da paratiróide, ao contrário, seriam mais resistentes à transformação neoplásica e requereriam um nível de expressão do RET mutante mais elevado para que sinais indutores de transformação celular pudessem ocorrer (16,21). Em resumo, um mutante mais abundante na superfície da membrana induziria o fenótipo completo da síndrome, com carcinoma medular de tiróide, feocromocitoma e adenoma de paratiróide. Ao contrário, formas mutantes com mais baixo nível de expressão celular não seriam capazes de gerar feocromocitoma ou hiperparatiroidismo, mas seriam suficientes para causar carcinoma medular de tiróide. Apesar deste modelo ser bastante abrangente, ainda há aspectos que permanecem por ser esclarecidos. Não se conhece, por exemplo, a base genética para a existência de feocromocitoma em apenas um subgrupo de casos com NEM 2A (50\%) com o mesmo tipo de mutação constitutiva do RET. Isto sugere que, semelhante ao que ocorre em NEM 2B, há outros fatores, de natureza ainda não esclarecida, que contribuem para a heterogeneidade clínica de NEM 2A e o desenvolvimento do feocromocitoma.

Apesar do alto índice de positividade na detecção de mutações, existe ainda um pequeno número de pacientes com NEM 2 nas quais não há uma mutação detectável no RET. Como não parece haver heterogeneidade genética nesta doença, ou seja, todas as famílias afetadas e testadas segregam com marcadores próximos ao locus do RET no cromossomo 10, estes pacientes possivelmente são portadores de mutações na região promotora ou mesmo intrônica (capazes, por exemplo, de afetar a eficiência do processo de splicing do gene), áreas que usualmente não são incluídas nos métodos tradicionais de triagem de mutações.

\section{FEOCROMOCITOMAS NA SÍNDROME DE VON HIP- PEL-LINDAU (VHL)}

A associação de feocromocitoma com a síndrome de von Hippel-Lindau (vHL) é bem conhecida (25). Contudo, diferente do que se observa em NEM 2, há uma enorme variabilidade clínica em vHL, com a presença de feocromocitoma variando amplamente entre famílias afetadas.
Este fato, somado a achados genotípicos com importante correlação com o fenótipo em vHL, levou a uma nova subclassificação da doença. São reconhecidas atualmente duas principais variantes de vHL, de acordo com a ausência ou presença de feocromocitoma, os tipos I e II, respectivamente (26-28). As manifestações descritas no tipo I são carcinoma renal, hemangioblastoma do sistema nervoso central (cerebelo, medula espinhal, retina), cistos de rim, pâncreas ou epidídimo. O grupo II, apresentando feocromocitoma, pode ser, por sua vez, dividido em três subtipos: IIA, representa famílias com alto risco de desenvolvimento de carcinomal renal, IIB, baixo risco de carcinoma renal e, mais recentemente, reconheceu-se o grupo IIC, na qual feocromocitoma apresenta-se como a única manifestação clínica da doença. Este último subgrupo de famílias com feocromocitoma, sem outros comemorativos da síndrome vHL possui mutação constitutiva no gene VHL. Estes casos, cuja freqüência ainda não está bem definida, parecem representar formas frustras de vHL (29-31).

Embora se estime que $10-15 \%$ dos feocromocitomas sejam herdados, um estudo realizado em uma população extensa de feocromocitomas da região da Floresta Negra, no sul da Alemanha, revelou um índice mais elevado de mutações constitutivas de VHL (46\% dos casos) (32). Como esta região é o local de origem de uma das mutações do VHL ("mutação fundadora"), este fato possivelmente gerou uma distorção nesta análise, uma vez que tal freqüência não foi encontrada em nenhuma outra população.

\section{FUNÇÃO DA PROTEÍNA VHL}

Os achados iniciais de LOH (perda de heterozigosidade) em neoplasias associadas com a síndrome vHL (especialmente de origem renal) sugeriram que o VHL é um gene supressor de tumor (33-36). Tais observações foram confirmadas por estudos in vitro quando se demonstrou que a reintrodução de uma cópia normal da proteína VHL em células mutantes resulta em regressão do fenótipo tumoral (37). Funcionalmente, foi demonstrado que esta proteína se liga a elonguinas $\mathrm{B} \mathrm{e} \mathrm{C}$ è à proteína Cul2 formando complexos capazes de reconhecer e "marcar" proteínas que serão posteriormente degradadas pelo sistema de ubiquitinação do proteassomo (46-48). Além disso, já se havia observado que a ausência de VHL resulta em um aumento da transcrição de genes estimulados por sinais de hipóxia $(38,39)$. Assim, a combinação destes dois fatos resultou na identificação do fator de indução de hipóxia, HIFl, como o principal substrato do complexo VHL/Elonguinas/ Cul2 (40). Sabe-se que as proteínas que são ativadas por hipóxia 
tentam restaurar ou se adaptar ao novo nível de oxigenação tissular através de mecanismos distintos, entre os quais a indução de angiogênese. Isto pode explicar o fato de que os tumores componentes da síndrome vHL são altamente vascularizados. Mutantes de VHL resultando em perda da sua função não inibem eficientemente a transcrição de $H I F l$, acarretando sinais que induzem proliferação celular (41).

Porém, além dos efeitos de VHL na regulação de sinais de hipóxia, outras funções têm sido atribuídas a esta proteína, tais como organização da matriz extracelular, controle do ciclo celular, estabilização de certos genes a nível pós-transcricional (42-44). Contudo, os mecanismos de regulação destas funções da proteína ainda não foram bem esclarecidos.

\section{ASSOCIAÇÕES GENÓTIPO-FENÓTIPO EM VHL}

Um importante achado relacionado com correlação genótipo-fenótipo em vHL é a marcante associação de mutações do tipo missense nos casos com feocromocitoma (96\% dos pacientes com tipo II), em contraste com uma alta frequiência de deleções do gene $V H L$ nos pacientes sem este tumor $(27,28,45)$. Além disso, foram encontradas específicas mutações que parecem se associar com maior freqüência à existência de feocromocitoma (tabela 2). Uma possível explicação para esta correlação se baseia no fato de que deleções de grandes porçôes da proteína VHL se associam com completa perda da sua função (descrita abaixo), enquanto que mutaçóes puntiformes levariam a uma perda apenas parcial da função de VHL, entre as quais a sua capacidade de se ligar a outras proteínas. Possivelmente esta função residual do VHL mutante seria importante para a célula da medula adrenal, e uma perda completa da sua função teria um efeito seletivo negativo para a proliferação desta célula e explicaria, assim, a ausência de feocromocitoma nos casos de vHL devidos a grandes deleções do gene VHL.

Esta hipótese é reforçada pelo achado freqüente de perda de heterozigosidade (LOH) ou metilação do gene VHL em carcinoma renal em pacientes com a síndrome clínica (46), ambos acarretando perda total da função protéica. Em comparação com este perfil dos tumores renais em vHL, a freqüência de $\mathrm{LOH}$ é menor em feocromocitomas e ainda não foram descritos tumores com metilação do VHL (47). Isto sugere que mutações de feocromocitoma em vHL exercem um efeito dominante negativo sobre a proteína VHL normal e, portanto, um fenótipo menos agressivo que a perda completa de sua função (48). Uma hipótese alternativa é que a dosagem deste gene seria criticamente importante para a sua função em certos tecidos-alvo e a ausência de um único alelo normal já poderia ocasionar o desenvolvimento de feocromocitomas, fenômeno conhecido como haploinsuficiência. Contudo, a favor da primeira hipótese estão os recentes achados de uma análise funcional de mutantes encontrados exclusivamente em vHL tipo IIC (casos com feocromocitoma isolado) $(49,50)$. Observou-se que estes mutantes mantêm a resposta aos sinais de hipóxia intactos, ao contrário dos mutantes encontrados nos demais subtipos de vHL, associados a hemangioblastomas e carcinoma renal. Contudo, apesar de conservar a regulação de sinais de hipóxia, os mutantes do tipo IIC apresentam defeitos na sua propriedade de organizar a matriz extracelular e se ligar à fibronectina, sugerindo que este papel da proteína VHL é importante para regular o crescimento da célula simpatoadrenal.

Embora um enorme progresso na caracterização biológica da proteína VHL tenha ocorrido nos últimos anos, ainda existem muitas questões abertas e se espera

Tabela 2. Correlação genotípica-fenotípica na síndrome de von Hippel-Lindau.

\begin{tabular}{|c|c|c|}
\hline Classificação & Fenótipo & Tipos de mutações constitutivas mais comuns do gene VHL \\
\hline Tipo I & $\begin{array}{l}\text { - Hemangioblastomas } \\
\text { - Carcinoma renal de células claras }\end{array}$ & $\begin{array}{l}46 \% \text { deleções } \\
10 \% \text { puntiformes do tipo nonsense } \\
44 \% \text { puntiforme do tipo missense }\end{array}$ \\
\hline $\begin{array}{r}\text { Tipo II } \\
\text { IIA }\end{array}$ & $\begin{array}{l}\text { - Feocromocitoma } \\
\text { - Hemangioblastomas } \\
\text { - Baixa freqüência de carcinoma renal } \\
\text { de células claras }\end{array}$ & $\begin{array}{l}96 \% \text { mutações puntiformes do tipo missense } \\
\text { Y98H Y } 112 \mathrm{H}\end{array}$ \\
\hline IIB & $\begin{array}{l}\text { - Feocromocitoma } \\
\text { - Hemangioblastomas } \\
\text { - Alta freqüência de carcinoma renal } \\
\text { de células claras }\end{array}$ & $\begin{array}{l}\text { V74G R161G R167W R167Q R167G L178P } \\
\text { L178Q L178V }\end{array}$ \\
\hline IIC & - Feocromocitoma isolado & L188V G114S F119S V84L V166F S68W \\
\hline
\end{tabular}


que em um futuro não muito distante estes avanços possam se reverter na possibilidade do uso terapêutico do VHL ou seus derivados para a reversão do fenótipo associado com a síndrome.

\section{FEOCROMOCITOMAS NA NEUROFIBROMATOSE TIPO} 1

O NF1 foi o primeiro gene responsável por uma desordem genética associada ao feocromocitoma a ser identificado. Mutações germinativas deste gene localizado no cromossomo $17 \mathrm{q}$ determinam a susceptibilidade à neurofibromatose tipo 1 (5l).

A neurofibromatose tipo 1 , componente do grupo de facomatoses, é uma desordem autossômica dominante cuja freqüência é de 1 em cada 3.500 a 4.000 nascimentos (52). Feocromocitomas são descritos em cerca de 1 a $5 \%$ dos pacientes afetados (53). Embora existam poucos estudos detalhando características específicas dos feocromocitomas em pacientes com neurofibromatose, uma recente revisão de múltiplas séries revelou que, com exceção de uma apresentação predominantemente unilateral (mais de $80 \%$ dos casos), não parece haver quaisquer outras peculiaridades em relação à apresentação clínica, diagnóstico, evolução ou tratamento que permitam identificar diferencialmente feocromocitomas associados com neurofibromatose daqueles que se desenvolvem em outras síndromes hereditárias (54). Como a neurofibromatose é uma doença polimórfica, com extensa variação clínica dentro de um mesmo grupo familiar, não está claramente estabelecido se a presença de feocromocitoma em um indivíduo afetado determina um aumento no risco de recorrência familiar do tumor em portadores de mutação no NF1 (55). O gene NFI possui uma das maiores taxas de mutações observadas entre os genes humanos e aproximadamente $50 \%$ dos casos de neurofibromatose representam mutaçôes de novo do NFI (56).

\section{FUNÇÃO DA NEUROFIBROMINA}

As mutações do NF1 identificadas em pacientes com neurofibromatose resultam em perda de função do seu produto protéico, sendo portanto considerado um clássico gene supressor de tumor (56). O gene NFI codifica uma proteína, neurofibromina, que possui função de GTPase, capaz de contrapor a ação estimuladora da via RAS que, por sua vez, é ativada através da fosforilação do segundo mensageiro intracelular GDP (guanidina difosfato) em GTP (guanidina trifosfato) (57). A ausência de neurofibromina resulta em perda do mecanismo de regulação negativa do $R A S$, culminando com um estado de proliferação celular sem controle $(\mathbf{5 5}, \mathbf{5 8}, 59)$. Os modelos in vivo de perda de função do NF1 (knockouts) têm sido uma valiosa fonte de informação sobre a ação deste gene: enquanto homozigosidade na perda do gene é letal, os camundongos heterozigóticos apresentam desenvolvimento acelerado de tumores semelhantes aos vistos na doença humana (60). Assim, o estudo dos animais $n \mathrm{fl}^{+/-}$tem oferecido importantes dados que permitem uma melhor caracterização do processo de tumorigênese desencadeado pela disfunção da neurofibromina (60).

\section{RELAÇÃO GENÓTIPO-FENÓTIPO EM NEUROFIBROMATOSE TIPO 1}

Apesar de ter sido identificado há mais de 10 anos como o gene da neurofibromatose tipo 1 , a disponibilidade de um detalhado perfil do espectro de mutações de NFI associadas a doença ainda é limitada (56). Possivelmente isto se deve à extensão do gene, que possui 60 exons (51), e à ausência de áreas de maior concentração de mutações (hot spots) $(51,55)$. Desta forma, a limitação de dados sobre as potenciais correlações genético-clínicas com respeito a aspectos particulares da doença, como a presença de feocromocitoma, ainda não são possíveis.

Um dos poucos estudos dedicados a elucidar específicas questôes moleculares associadas ao feocromocitoma nesta doença investigou deleção do cromossomo 17 e expressão do gene NFI em uma pequena série de tumores (61). Os seguintes achados foram observados: a) a maior parte dos tumores apresentava $\mathrm{LOH}$ envolvendo o locus do NF1; b) os tumores apresentavam níveis reduzidos ou ausentes de transcrição de NFI. Uma extensão deste estudo em feocromocitomas de pacientes sem neurofibromatose revelou que o transcrito predominante nos tumores era uma forma de splicing (processamento) alternativo do RNA do NFI distinta do transcrito mais abundante em medula adrenal normal (62). O transcrito predominante em feocromocitomas exclui o exon 23 do gene NF1. Como este estudo não aborda potenciais implicações funcionais deste achado, sua importância biológica ainda está por ser determinada.

\section{COMPLEXO MITOCONDRIAL TIPO II - A FAMÍLIA DE SUCCINATO-DESIDROGENASES (SDHS)}

Recentemente, o gene responsável pela susceptibilidade à síndrome de paraganglioma familiar (PGL 1) foi identificado (63). PGL l é uma doença autossômica dominante de origem embriológica semelhante ao feocromocitoma, mas que resulta na formação de 
tumores de origem ganglionar parassimpática não cromafim, predominantemente localizados no corpo carotídeo (também conhecidos como quemodectomas). Este gene, SDHD (succinato desidrogenase tipo D), localizado na região subcromossômica llq23.3, codifica a subunidade menor da enzima succinato-desidrogenase, componente do complexo mitocondrial tipo II (64). Este complexo regula sinais responsivos ao nível de oxigênio e é composto por quatro subunidades, denominadas $\mathrm{A}, \mathrm{B}, \mathrm{C}$ e $\mathrm{D}$, de acordo com o peso molecular de cada proteína. Enquanto as subunidades A e B representam a porção catalítica do complexo, as subunidades C e D são responsáveis por ancorar as primeiras na porção interna da membrana mitocondrial (65). As mutações do SDHD identificadas nas famílias afetadas são do tipo nonsense na maioria dos casos e, embora o estudo inicial não tenha incluído uma análise funcional dos mutantes, é provável que as mutações associadas com a doença resultem na perda de função da succinato desidrogenase. Esta ausência funcional de SDHD que ocorre na PGL 1 pode potencialmente levar a um estado crônico de hipóxia que, por sua vez, seria capaz de desencadear respostas proliferativas do tecido alvo. Um outro tipo de síndrome de paraganglioma familiar, o tipo 3 (PGL 3), foi associado recentemente com mutação do gene que codifica a subunidade $S D H C$ (66), sugerindo que esta via biológica parece representar um importante mecanismo de regulação da proliferação de tecidos neuroectodérmicos.

Como mencionado acima, alterações na regulação de hipóxia estão envolvidas na patogênese de feocromocitomas associados com a síndrome de von Hippel-Lindau. É possível, portanto, especular que genes que codificam proteínas envolvidas no sistema de controle e sinalização de oxigênio representem importantes candidatos para a patogênese do feocromocitoma. Contudo, a julgar por estudos recentes do nosso e de outros grupos (67-69), é possível que mutações de $S D H D$ estejam predominantemente associadas a casos de específicos de feocromocitoma extraadrenal e/ou associados a paragangliomas de cabeça e pescoço e possam representar apenas uma pequena fração dos casos de feocromocitoma familiar. Até o presente, foi identificada uma mutação do $S D H D \mathrm{em}$ uma única família com feocromocitoma, entre as cinco famílias estudadas até o momento $(67,68)$. Os indivíduos afetados desta família apresentam feocromocitoma extra-adrenal e um dos membros da família foi diagnosticado com tumores carotídeos, semelhantes ao quadro observado em PGL l (68). O pequeno número de casos analisados até o momento não per- mite ainda atingir conclusões definitivas em relação a associações genotípicas-fenotípicas. O estudo de séries maiores poderá confirmar se as mutações de $S D H D$ são de fato mais comuns em casos de feocromocitoma extra-adrenal. Outros membros deste complexo mitocondrial são candidatos naturais para investigação em feocromocitomas: o seu estudo permitirá verificar a real relevância desta via metabólica para a patogênese destes tumores. Assim, dados preliminares do nosso grupo sugerem que um percentual significativo destas famílias apresentam alterações de outros membros deste complexo enzimático, como o SDHB (69b).

\section{OUTRAS FORMAS DE FEOCROMOCITOMA FAMILIAR}

Além das síndromes descritas acima que apresentam em comum a presença de feocromocitoma, existe evidência a favor de formas familiares adicionais deste tumor. Existem descrições na literatura da associação de feocromocitoma com insulinoma (70) e alguns casos de feocromocitoma foram descritos em pacientes com esclerose tuberosa. Por causa do pequeno número de casos e da inexistência de estudos abrangentes envolvendo uma análise clínico-epidemiológica detalhada, pouco é sabido sobre aspectos específicos destas associações, a ponto de ser possível definir com precisão o seu caráter hereditário: por exemplo, não se pode excluir que estes casos sejam apenas expressão coincidental de síndromes hereditárias distintas, ou mesmo de tumores esporádicos que coexistem no mesmo indivíduo.

Existe, contudo, uma clara entidade constituída de feocromocitoma familiar isolado, sem outras associações clínicas. Como mencionado acima, uma fração ainda não bem caracterizada destes casos parece representar uma forma frustra de vHL (29-31). Além disso, os dados mais recentes de estudos dos genes componentes do complexo II mitocondrial descritos acima parecem sugerir que algumas famílias com feocromocitoma extra-adrenal em associação a paraganglioma de corpo carotídeo podem ser causadas por mutações de $S D H D$ ou $S D H B(68,69 b)$.

Portanto, existe um claro grupo de famílias com feocromocitoma isolado nas quais não foram detectadas mutações de VHL ou SDHD (67-69b). O mapeamento da área cromossômica associada com o fenótipo nestas famílias é um projeto presentemente em andamento e liderado pelo nosso grupo que conta com a participação de um grupo internacional de pesquisadores, membros do Consórcio Internacional para o Mapeamento do Feocromocitoma Familiar Isolado. $\mathrm{O}$ estudo se baseia na análise conhecida como 
genome-wide scan. Este método utiliza marcadores polimórficos do tipo microssatélite distribuídos por todo o genoma a espaços regulares (10 centiMorgans), e tem sido usado amplamente para a identificação de regiões cromossômicas que segregam com doenças monogênicas (71). No momento, este projeto de mapeamento consta de famílias brasileiras, americanas e européias que preenchem os critérios definidos pelo Consórcio. Estes critérios envolvem a exclusão clínica e, quando possível, também molecular, de NEM 2, vHL, neurofibromatose tipo 1 e PGL 1 ou 3 em indivíduos com diagnóstico de feocromocitoma em mais de um membro da família. Como não existem dados definidos em relação à existência de heterogeneidade genética nesta síndrome, é possível que a caracterização de "ligação genética" (linkage) seja factível utilizando-se um grupo pequeno de famílias. Contudo, a confirmação da região associada à doença, bem como uma definição mais precisa do locus-alvo se beneficiaria da análise de um grande número de famílias afetadas. O recrutamento de novas famílias é, portanto, altamente relevante para atingir resultados estatisticamente robustos. Detalhes sobre a participação no Consórcio Internacional para o Mapeamento de Feocromocitoma Familiar estão disponíveis no endereço para correspondência descrito neste artigo.

\section{FEOCROMOCITOMAS ESPORÁDICOS}

Enquanto os avanços no conhecimento da base genética das raras formas de feocromocitoma hereditário foram abundantes nos últimos anos, pouco se progrediu em relação à caracterização de genes responsáveis pelo grupo mais numeroso de feocromocitomas, constituído pelos tumores esporádicos. Várias anormalidades genéticas foram identificadas em feocromocitomas, entre as quais áreas comuns de deleção, onde se observa constante perda de heterozigosidade no tecido tumoral.

\section{Áreas cromossômicas afetadas em feocromocitomas}

Alterações nas sub-regiões cromossômicas lp, 3p, 17p e 22q têm sido reconhecidas em feocromocitomas há vários anos (72-76).Um estudo recente mapeando em maior detalhe a região de deleção no cromossomo lp34-36 identificou três principais áreas de deleção, denominadas PC1, PC2 e PC3 (77). Este achado sugere que possivelmente três genes supressores de tumor distintos, localizados nesta região, exercem um papel na patogênese do feocromocitoma. Um fato digno de menção e observado em mais de um estudo é o achado de alta frequiência de LOH nesta região, não somente em tumores esporádicos (aproximadamente $60 \%$ dos casos), como também em feocromocitomas de pacientes com NEM 2 (47,77). Em contraste com $\mathrm{o}$ alto índice de $\mathrm{LOH}$ em lp neste tipo de feocromocitoma, um subgrupo de tumores parece contrastar de forma marcante: em feocromocitomas derivados de pacientes com vHL, foi observada baixa freqüência de LOH em lp e 22q concomitante a uma elevada frequiência de $\mathrm{LOH}$ na região $3 \mathrm{p}$ (onde se localiza o gene VHL). Um padrão de deleção inverso foi visto em tumores de pacientes sem vHL: nestes, foi detectada uma elevada freqüência (> 70\%) de deleção em lp e menos de um quarto dos casos apresentaram $\mathrm{LOH}$ na região $3 \mathrm{p}$. $\mathrm{O}$ achado de ambos os estudos sugere que os mecanismos envolvidos na patogênese de feocromocitomas de origens distintas parecem divergir $(47,77)$. Contudo, vale a pena ressaltar que as anormalidades do cromossomo 1 são observadas não somente em tumores esporádicos, mas também em casos de NEM 2, onde o defeito genético primário já é conhecido (mutação do RET), indicando que a alteração no cromossomo 1 parece se tratar de um evento mais tardio na progressão do tumor, e possivelmente $\mathrm{o}(\mathrm{s})$ gene(s) envolvidos nesta área não representa $(\mathrm{m}) \mathrm{o}$ elemento iniciador do desenvolvimento tumoral. Um recente estudo, contudo, utilizando a técnica de hibridização genômica comparativa $(\mathrm{CGH})$ para análise global de alterações genéticas em feocromocitomas adrenais e extra-adrenais concluiu que deleções do cromossomo lp não parecem ocorrer em uma fase muito tardia da evolução do tumor (78). Estas discrepâncias podem ser resultado de variações de sensibilidade dos métodos utilizados ou do estudo de populações distintas. A análise de $\mathrm{CGH}$ identificou diversas áreas de deleção (essencialmente as regiões previamente caracterizadas por apresentar $\mathrm{LOH}$ ), além de algumas áreas de amplificação neste grupo de tumores (tabela 3). É

Tabela 3. Anormalidades moleculares em feocromocitomas esporádicos.

\begin{tabular}{ll}
\hline $\begin{array}{l}\text { Áreas de } \mathrm{LOH} \\
\text { (freqüência em \%) }\end{array}$ & $\begin{array}{l}\text { Áreas de ganho cromossômico } \\
\text { (freqüência em \%) }\end{array}$ \\
\hline $1 \mathrm{p}(40-80)$ & 11 cen-q13 (15) \\
$3 \mathrm{p}(15-30)$ & $16 p(15)$ \\
$3 \mathrm{q}\left(40^{\star}\right)$ & $17 q 24-q$ ter $(21)$ \\
$11 \mathrm{p}(26)$ & $19 p(26)$ \\
$11 \mathrm{q}(15)$ & $19 q(24)$ \\
$17 q(10-20)$ & \\
$22 \mathrm{q}(20-40)$ & \\
\hline
\end{tabular}

*achado de um único estudo (78). 
possível que estudos envolvendo as áreas acima revelem a existência de genes que funcionem como oncogenes, ao invés de supressores de tumor, potencialmente capazes de contribuir para a patogênese do feocromocitoma.

\section{Análise de genes candidatos em feocromocitomas esporádicos}

A estratégia da análise de genes candidatos baseados na sua biologia e potencial relevância para a regulação da célula simpatoadrenal, incluindo os genes associados com as síndromes familiares de feocromocitoma, foi vastamente empregada nos últimos anos para o estudo das variantes esporádicas do tumor. Assim, o nosso e vários outros grupos investigaram a seqüência dos genes RET e VHL $(25,79-83)$, bem como os genes que codificam proteínas associadas com estes, como, por exemplo, o ligante do RET, GDNF (84), e uma proteína - CUL2 (85) - que forma complexos com VHL nestes tumores. Estes estudos resultaram em um baixo número ou mesmo ausência de mutações somáticas nos diversos grupos de feocromocitomas analisados. Mais recentemente, a análise do gene $S D H D$ em três séries independentes de feocromocitomas resultou na detecção de uma única mutação somática em um total de $\mathbf{5 8}$ tumores esporádicos (67-69).

Além destes genes candidatos com enfoque em específicos componentes de vias funcionais do tecido neuroectodérmico, outros genes associados com mutações freqüentes em diversas neoplasias humanas também foram alvo de extensa investigação. A análise do gene supressor de tumor p53 revelou resultados conflitantes: a maior parte dos estudos, incluindo um do nosso grupo, não detectou mutações em feocromocitomas (86-90), enquanto, em uma pequena série, mutações foram identificadas no exon $4 \mathrm{em}$ alguns tumores (91). Em um estudo mais recente, foram identificadas mutações do p53 em alguns tumores malignos (92). Deleções do gene pl6, inibidor do ciclo celular a cuja perda de função foi associada certas formas de melanoma familiar e diversas neoplasias esporádicas, também não foram detectadas em nossa série de feocromocitomas (93). Em resumo, os mecanismos genéticos responsáveis pelo fenótipo tumoral esporádico ainda estão por ser elucidados.

\section{CONCLUSÕES E ESTUDOS FUTUROS}

Estudos utilizando extensas séries de feocromocitomas, tanto de origem hereditária como esporádica, nas quais uma detalhada análise molecular, incluindo a determinação do perfil genotípico e transcricional destes tumores serão relevantes para uma melhor compreensão dos mecanismos patogenéticos do feocromocitoma. Em tais estudos, é possível se determinar através do uso de chips ou microarrays, a análise multiparalela de genes. Chips são painéis miniaturizados nas quais amostras de milhares de genes (as versões mais recentes destes painéis contêm até 10.000 genes conhecidos e cerca de 20.000 a 30.000 seqüências ainda não bem caracterizadas) são fixadas em uma superfície sólida de pequenas dimensões e hibridizadas com o RNA (no caso dos arrays de expressão) ou DNA genômico (no caso dos arrays de polimorfismos) de amostras a ser testadas. Neste sentido, iniciamos recentemente um esforço internacional que tem como

Tabela 4. Sumário das principais alterações moleculares em feocromocitomas.

\begin{tabular}{|c|c|c|c|c|}
\hline Tipo de feocromocitoma & $\begin{array}{l}\text { Mutações } \\
\text { do RET }\end{array}$ & $\begin{array}{l}\text { Mutações do } \\
\text { gene VHL }\end{array}$ & $\begin{array}{l}\text { Mutações do } \\
\text { gene NF1 }\end{array}$ & $\begin{array}{l}\text { Mutações dos } \\
\text { genes SDHD/SDHB }\end{array}$ \\
\hline \multicolumn{5}{|l|}{ Familiar } \\
\hline NEM 2A & $96 \%$ & - & - & - \\
\hline NEM 2B & $98 \%$ & - & - & - \\
\hline $\mathrm{vHL}$ & - & $99 \%$ & - & - \\
\hline $\begin{array}{l}\text { Neurofibromatose } \\
\text { Feocromocitoma }\end{array}$ & - & - & $>50 \% *$ & - \\
\hline associado a paraganglioma & - & - & - & possivelmente alto?\# \\
\hline Feocromocitoma isolado & - & $40-50 \% \pi$ & - & possivelmente baixo\# \\
\hline Esporádico & $1-5 \%$ & $1-3 \%$ & $?$ & $1 \%$ \\
\hline
\end{tabular}


objetivo recrutar o maior número possível de casos de feocromocitoma de diversas origens genéticas, bem como tumores esporádicos, para detalhada caracterização genética, epigenética e transcricional. Tais estudos são criticamente importantes para definir vias comuns que contribuem para a progressão e desenvolvimento do tumor, permitindo a elucidação de mecanismos intracelulares responsáveis pela perda de controle de proliferação de células simpatoadrenais. Antecipa-se que este tipo de análise possa também indicar genes ou vias regulatórias que estejam implicadas, por exemplo, na determinação do fenótipo maligno de alguns tumores. Da mesma forma, vias específicas e particulares a cada síndrome hereditária também serão dissecadas em maior detalhe, delineando as diversas origens dos defeitos iniciadores do processo de gênese de feocromocitoma, bem como oferecendo informações sobre novas interações entre vias regulatórias não previamente caracterizadas ou suspeitadas. Além da massa de informações geradas pela análise de amostras tumorais, tais estudos também serão capazes de revelar importantes dados em relação à regulação intracelular da medula adrenal normal.

De forma análoga, a análise multiparalela de uma população heterogênea de feocromocitomas a nível genômico (através de arrays de polimorfismos, por exemplo) poderá fornecer a base para estudos detalhados caracterizando específicas áreas do genoma que são indistintamente afetadas em diversos subtipos de feocromocitoma, como o cromossomo lp, em contraste com regiões afetadas em apenas um subgrupo de tumores. Estes estudos proporcionarão dados que permitem elucidar mecanismos de progressão tumoral. Espera-se que este tipo de análise também possa fornecer informações em relação a fatores que possam modular o fenótipo e se associem com a variabilidade clínica da doença vista na maioria das síndromes hereditárias.

Com a caracterização detalhada do genoma e o mapeamento refinado de genes conhecidos e da identificação de novos genes, espera-se que o progresso na caracterização das bases moleculares dos feocromocitomas será considerável num futuro próximo.

\section{AGRADECIMENTOS}

Agradeço ao Dr. Ricardo Aguiar pelos comentários e discussões sobre esta revisão e aos colegas participantes do nosso Consórcio Internacional para o Mapeamento de Feocromocitoma Familiar pela sua importante contribuição com amostras de indivíduos pertencentes a famílias afetadas: Sérgio P.A. Toledo, César Hayashida (FMUSP, São Paulo), Ana Valéria de Castro, Célia
Nogueira (UNESP - Botucatu, SP), T.J. Lennard, Fiona Douglas (University of Newcastle, Newcastle, UK), Ashley Grossman (St. Bartholomew's Hospital, London, UK), Judy Garber, Kathy Schneider, E. Hiller (Dana-Farber Cancer Institute, Boston-MA, USA), Roswitha Pfragner (Karl-Franzens-Universität Graz, Áustria), George Kontogeorgos (Athens General Hospital, Atenas, Grécia).

\section{REFERÊNCIAS}

1. Bravo EL, Gifford RW. Pheochromocytoma: Diagnosis, localization and management. N Engl J Med 1984;30: 1682-6.

2. de la Chapelle A, Eng C. Molecular genetic diagnosis in hereditary cancer. In: ASCO Educational Book, Perry MC, ed. Baltimore: Lippincott, Williams and Wilkins, 1999, p.44553.

3. Eng $C$, Stratton $M$, Ponder B, et al. Familial cancer syndromes. Lancet 1994;343:709-13.

4. Mulligan LM, Kwok JBJ, Healey CS, et al. Germline mutations of the RET proto-oncogene in multiple endocrine neoplasia type 2A. Nature 1993;363:458-60.

5. Donis-Keller H, Dou $\mathrm{S}$, Chi $\mathrm{D}$, et al. Mutations in the RET proto-oncogene are associated with MEN 2A and FMTC. Hum Mol Genet 1993;2:851-6.

6. Eng C, Mulligan LM. Mutations of the RET proto-oncogene in multiple endocrine neoplasia type 2, related sporadic tumors and Hirschsprung diseases. Hum Mutat 1997;9:97109.

7. Takahashi M, Cooper GM. Ret transforming gene encodes a fusion protein homologous to tyrosine kinases. Mol Cell Biol 1987;7:1378-85.

8. Lin L-FH, Doherty DH, Lile JD, Bektesh S, Collins FS. GDNF: a glial cell line-derived neurotrophic factor for midbrain dopamingergic neurons. Science 1993;260:1130-2.

9. Jing $S$, Wen $D, Y u Y$, et al. GDNF-induced activation of the Ret protein tyrosine kinase is mediated by GDNFR-a, a novel receptor for GDNF. Cell 1996;85:1113-24.

10. Durbec $P$, Marcos-Gutierrez CV, Kilkenny C, et al. Glial cell line-derived neurotrophic factor signaling through the Ret receptor tyrosine kinase. Nature 1996;381:789-93.

11. Melillo RM, Barone MV, Lupoli G, et al. Ret-mediated mitogenesis requires Src kinase activity. Cancer Res 1999;59:1 120-6.

12. Ohiwa $M$, Murakami $H$, Iwashita $T$, et al. Characterization of Ret-Shc-Grb2 complex induced by GDNF, MEN 2A, and MEN 2B mutations. Biochem Biophys Res Commun 1997;237:747-51.

13. Pandey A, Duan H, Di Fiore PP, Dixit VM. The Ret receptor protein tyrosine kinase associates with the $\mathrm{SH} 2$-containing adapter protein Grb10. J Biol Chem 1995;270:21461-3.

14. Segouffin-Cariou C, Billaud M. Transforming ability of MEN2A-RET requires activation of the phosphatidylinositol 3Kinase/AKT signaling pathway. J Biol Chem 2000;275:356876.

15. Mulligan LM, Eng C, Healey CS, et al. Specific mutations of 
the RET proto-oncogene are related to disease phenotype in MEN 2A and FMTC. Nature Genet 1994;6:70-4.

16. Mulligan LM, Eng C, Attié T, et al. Diverse phenotypes associated with exon 10 mutations of the RET proto-oncogene. Hum Mol Genet 1994;3:2163-7.

17. Borrello MG, Smith DP, Pasini B, et al. RET activation by germline MEN2A and MEN2B mutations. Oncogene 1995; 11:2419-27.

18. Eng $C$, Smith DP, Mulligan LM, et al. Point mutation within the tyrosine kinase domain of the RET proto-oncogene in multiple endocrine neoplasia type $2 \mathrm{~B}$ and related sporadic tumors. Hum Mol Genet 1994;3:237-41.

19. Gimm O, Marsh DJ, Andrew SD, et al. Germline dinucleotide mutation in codon 883 of the RET proto-oncogene in multiple endocrine neoplasia type $2 B$ without codon 918 mutation. J Clin Endocrinol Metab 1997;82:3902-4.

20. Songyang Z, Carraway III KL, Eck MJ, et al. Catalytic specificity of protein-tyrosine kinases is critical for selective signaling. Nature 1995;373: 536-9.

21. Mulligan LM, Marsh DJ, Robinson BG, et al. Genotype-phenotype correlation in MEN 2: Report of the International RET Mutation Consortium. J Intern Med 1995;238: 343-6.

22. Machens A, Gimm O, Hinze R, Hoppner W, Boehm BO, Dralle H. Genotype-phenotype correlations in hereditary medullary thyroid carcinoma: oncological features and biochemical properties. J Clin Endocrinol Metab 2001;86:1104-9.

23. Ito S, Iwashita $\mathrm{T}$, Asai N, et al. Biological properties of Ret with cysteine mutations correlate with multiple endocrine neoplasia type $2 \mathrm{~A}$, familial medullary thyroid carcinoma, and Hirschsprung's disease phenotype. Cancer Res 1997;57: 2870-2.

24. Iwashita T, Murakami H, Asai N, Takahashi M. Mechanisms of Ret dysfunction by Hirschsprung mutations affecting its extracellular domain. Hum Mol Genet 1996;5:1577-80.

25. Maher ER, Kaelin WG, Jr. von Hippel-Lindau disease. Medicine (Balt) 1997;76:381-91.

26. Chen F, Kishida T, Yao M, et al. Germline mutations in the von Hippel-Lindau disease tumor suppressor gene: correlations with phenotype. Hum Mutat 1995;5:66-75.

27. Maher E, Webster A, Richards F, et al. Phenotypic expression in von Hippel-Lindau disease: Correlations with germline VHL gene mutations. J Med Genet 1996;33:32832.

28. Neumann H, Bender B. Genotype-phenotype correlations in von Hippel-Lindau disease. J Intern Med 1998 1998;243:541-5.

29. Gross DJ, Avishai N, Meiner V, Filon D, Zbar B, Abeliovich D. Familial pheochromocytoma associated with a novel mutation in the von Hippel-Lindau gene. J Clin Endocrinol Metab 1996;81:147-9.

30. Ritter MM, Frilling A, Crossey PA, et al. Isolated familial pheochromocytoma as a variant of von Hippel-Lindau disease. J Clin Endocrinol Metab 1996;81:1035-7.

31. Woodward ER, Eng C, McMahon R, et al. Genetic predisposition to phaeochromocytoma: analysis of candidate genes GDNF, RET and VHL. Hum Mol Genet 1997;6:1051-6.

32. Neumann HP, Berger DP, Sigmund G, ef al. Pheochromocy- tomas, multiple endocrine neoplasia type 2, and von HippelLindau disease. N Engl J Med 1993;329:1531-8.

33. Whaley JM, Naglich J, Gelbert L, et al. Germ-line mutations in the von Hippel-Lindau tumor suppressor gene are similar to somatic von Hippel-Lindau aberrations in sporadic renal cell carcinoma. Am J Hum Genet 1994;55:1092-102.

34. Shuin T, Kondo K, Torigoe S, et al. Frequent somatic mutations and loss of heterozygosity of the von Hippel-Lindau tumor suppressor gene in primary human renal cell carcinomas. Cancer Res 1994;54:2852-5.

35. Gnarra JR, Lerman MI, Zbar B, Linehan WM. Genetics of renal-cell carcinoma and evidence for a critical role for von Hippel-Lindau in renal tumorigenesis. Semin Oncol 1995;22:3-8.

36. Prowse AH, Webster AR, Richards FM, et al. Somatic inactivation of the VHL gene in Von Hippel-Lindau disease tumors. Am J Hum Genet 1997;60:765-71.

37. Iliopoulos O, Kibel A, Gray S, Kaelin WG, Jr. Tumor suppression by the human von Hippel-Lindau gene product. Nat Med 1995; 1:822-6.

38. Lonergan $\mathrm{KM}$, lliopoulos $\mathrm{O}$, Ohh $\mathrm{M}$, et al. Regulation of hypoxia-inducible mRNAs by the von Hippel-Lindau tumor suppressor protein requires binding to complexes containing elongins $\mathrm{B} / \mathrm{C}$ and Cul2. Mol Cell Biol 1998; 18:732-41.

39. Maxwell PH, Wiesener MS, Chang GW, et al. The tumor suppressor protein VHL targets hypoxia-inducible factors for oxygen-dependent proteolysis. Nature 1999;399:271-5.

40. Semenza GL. HIF-1: mediator of physiological and pathophysiological responses to hypoxia. J Appl Physiol 2000;88:1474-80.

41. Kaelin WG, lliopoulos O, Lonergan KM, Ohh M. Functions of the von Hippel-Lindau tumor suppressor protein. J Intern Med 1998;243:535-9.

42. Pause A, Lee S, Lonergan KM, Klausner RD. The von HippelLindau tumor suppressor gene is required for cell cycle exit upon serum withdrawal. Proc Natl Acad Sci USA 1998;95:993-8.

43. Ohh M, Park CW, Ivan M, et al. Ubiquitination of hypoxiainducible factor requires direct binding to the beta-domain of the von Hippel-Lindau protein. Nat Cell Biol 2000;2:4237.

44. Kondo K, Kaelin WG. The von Hippel-Lindau tumor suppressor gene. Exp Cell Res 2001;264:117-25.

45. Chen F, Kishida T, Yao M, et al. Germline mutations in the Von Hippel-Lindau disease tumor suppressor gene: correlations with phenotype. Hum Mutat 1995;5:66-75.

46. Herman JG LF, Weng Y, Lerman MI, Zbar B, Liu S, Samid D, et al. Silencing of the VHL tumor-suppressor gene by DNA methylation in renal carcinoma. Proc Natl Acad Sci USA 1994;91:9700-4.

47. Bender BU, Gutsche M, Gläsker S, et al. Differential genetic alterations in von Hippel-Lindau syndrome-associated and sporadic pheochromocytomas. J Clin Endocrinol Metab 2000;85:4568-74.

48. Duan DR, Pause A, Burgess WH, et al. Inhibition of transcription elongation by the VHL tumor suppressor protein. Science 1995;269:1402-6.

49. Clifford SC, Cockman ME, Smallwood AC, et al. Contrasting 
effects on HIF-lalpha regulation by disease-causing $\mathrm{pVHL}$ mutations correlate with patterns. Hum Mol Genet 2001;10:1029-38.

50. Hoffman MA, Ohh M, Yang H, Klco JM, Ivan M, Kaelin Jr. WG. von Hippel-Lindau protein mutants linked to type $2 \mathrm{C}$ VHL disease preserve the ability to down regulated HIF. Hum Mol Genet 2001;10:1019-27.

51. Viskochil D, Buchberg AM, Xu G, et al. Deletions and translocation interrupt a cloned gene at the neurofibromatosis type 1 locus. Cell 1990;62:187-92.

52. McKusick VA. Mendelian Inheritance in Man. Baltimore: Johns Hopkins University Press, 1992.

53. Riccardi VM. von Recklinghausen neurofibromatosis. N Engl J Med 1981;305:1617-27.

54. Walther MM, Herring J, Enquist E, Keiser HR, Linehan WM. von Recklinghausen's disease and pheochromocytomas. J Urol 1999;162:1582-6.

55. Upadhyaya M, Maynard J, Osborn M, et al. Characterization of germline mutations in the neurofibromatosis type 1 (NF1) gene. J Med Genet 1995;32:706-10.

56. Ars E, Serra E, Garcia J, et al. Mutations affecting mRNA splicing are the most common molecular defects in patients with neurofibromatosis type 1. Hum Mol Genet 2000;9:237-47.

57. Cichowski K, Jacks T. NF1 tumor suppressor gene function: narrowing the GAP. Cell 2001;104:593-604.

58. Wallace MR, Marchuk DA, Anderson LB, et al. Type 1 neurofibromatosis gene: identification of a large transcript disrupted in three NF 1 patients. Science 1990;249: 181-6.

59. Ward K, O'Connell P, Carey J, et al. Diagnosis of neurofibromatosis 1 by using tightly linked, flanking DNA markers. Am J Hum Genet 1990;46:943-9.

60. Brannan $\mathrm{Cl}$, Perkins AS, Vogel KS, et al. Targeted disruption of the neurofibromatosis type-1 gene leads to developmental abnormalities in heart and various neural crestderived tissues. Genes Dev 1994;8:1019-29.

61. Gutmann DH, Cole JL, Stone WJ, Ponder BA, Collins FS. Loss of neurofibromin in adrenal gland tumors from patients with neurofibromatosis type I. Genes Chromosomes Cancer 1994; 10:55-8.

62. Gutmann DH, Geist RT, Rose K, Wallin G, Moley JF. Loss of neurofibromatosis type I (NF1) gene expression in pheochromocytomas from patients without NF1. Genes Chromosomes Cancer 1995;13:104-9.

63. Baysal BE, Ferrell RE, Willett-Brozick JE, et al. Mutations in SDHD, a mitochondrial complex II gene, in hereditary paraganglioma. Science 2000;287:848-51.

64. Hirawake H, Taniwaki M, Tamura A, Amino H, Tomitsuka E, Kita K. Characterization of the human SDHD gene encoding the small subunit of cytochrome $b$ (cybS) in mitochondrial succinate-ubiquinone oxidoreductase. Biochim Biophys Acta 1999; 1412:295-300.

65. Hirawake H, Taniwaki M, Tamura A, Kojima S, Kita K. Cytochrome $b$ in human complex II (succinate-ubiquinone oxidoreductase): cDNA cloning of the components in liver mitochondria and chromosome assignment of the genes for the large (SDHC) and small (SDHD) subunits to 1q21 and 11q23. Cytogenet Cell Genet 1997;79:132-8.
66. Niemann S, Müller U. Mutations in SDHC cause autosomal dominant paraganglioma, type 3. Nat Genet 2000;26:26870.

67. Aguiar RCT, Cox G, Pomeroy S, Dahia PLM. Analysis of the $S D H D$ gene, the susceptibility gene for familial paraganglioma syndrome (PGL1), in pheochromocytomas. J Clin Endocrinol Metab 2001;86:2890-4.

68. Astuti D, Douglas F, Lennard TWJ, et al. Germline SDHD mutation in familial phaeochromocytoma. Lancet 2001;357:1181-2.

69. Gimm O, Armanios M, Dziema H, Neumann HP, Eng C. Somatic and occult germ-line mutations in SDHD, a mitochondrial complex II gene, in nonfamilial pheochromocytoma. Cancer Res 2000;60:6822-5.

69b. Astuti D, Latif F, Dallol A, Dahia PL, Douglas F, George E, et al. Gene mutations in the succinate dehydrogenase subunit SDHB cause susceptibility to familial pheochromocytoma and to familial paraganglioma. Am J Hum Genet 2001;69:49-54.

70. Zeller JR, Kauffman HM, Komorowski RA, Itskovitz HD. Bilateral pheochromocytoma and islet cell adenoma of the pancreas. Arch Surg 1982;117:827-30.

71. Aguiar RCT, Dahia PLM. Identification and characterization of disease-related genes: focus on endocrine neoplasias. In: Genetic Disorder of Endocrine Neoplasia (1 st ed). Dahia PLM, Eng C, eds. Basel: Karger, 2001, p.20-49.

72. Khosla S, Patel VM, Hay ID, et al. Loss of heterozygosity suggests multiple genetic alterations in pheochromocytomas and medullary thyroid carcinomas. J Clin Invest 1991;87:1691-9.

73. Moley JF, Brother MB, Fong CT, et al. Consistent association of $1 p$ loss of heterozygosity with pheochromocytomas from patients with multiple endocrine neoplasia type 2 syndromes. Cancer Res 1992;52:770-4.

74. Tanaka N, Nishisho I, Yamamoto M, et al. Loss of heterozygosity on the long arm of chromosome 22 in pheochromocytoma. Genes Chromosomes Cancer 1992;5:399-403.

75. Shin E, Fujita S, Takami K, et al. Deletion mapping of chromosome $1 p$ and $22 q$ in pheochromocytoma. Jpn J Cancer Res 1993;84:402-8.

76. Vargas MP, Zhuang Z, Wang C, Vortmeyer A, Linehan WM, Merino MJ. Loss of heterozygosity on the short arm of chromosomes 1 and 3 in sporadic pheochromocytoma and extra-adrenal paraganglioma. Hum Pathol 1997;28:41 1-5.

77. Benn DE, Dwight T, Richardson AL, et al. Sporadic and familial pheochromocytomas are associated with loss of at least two discrete intervals on chromosome 1p. Cancer Res 2000;60:7048-51.

78. Edstrom E, Mahlamaki E, Nord B, et al. Comparative genomic hybridization reveals frequent losses of chromosomes $1 p$ and $3 q$ in pheochromocytomas and abdominal paragangliomas, suggesting a common genetic etiology. Am J Pathol 2000; 156:651-9.

79. Eng C, Crossey PA, Mulligan LM, et al. Mutations in the RET proto-oncogene and the von Hippel-Lindau disease tumor suppressor gene in sporadic and syndromic phaeochromocytomas. J Med Genet 1995;32:934-7.

80. Lindor NM, Honchel R, Khosla S, Thibodeau SN. Mutations in the RET protooncogene in sporadic pheochromocytomas. J Clin Endocrinol Metab 1995;80:627-9. 
81. Beldjord B, Desclaux-Arramond F, Raffin-Sanson M, et al. The RET proto-oncogene in sporadic pheochromocytomas: frequent MEN 2-like mutations and new molecular defects. J Clin Endocrinol Metab 1995;80:2063-8.

82. Komminoth $P$, Roth J, Muletta-Feurer S, Saremaslani P, Seelentag WK, Heitz PU. RET proto-oncogene point mutations in sporadic neuroendocrine tumors. J Clin Endocrinol Metab 1996;81:2041-6.

83. Brauch H, Hoeppner W, Jahnig H, et al. Sporadic pheochromocytomas are rarely associated with germline mutations in the vhl tumor suppressor gene or the ret protooncogene. $\mathrm{J}$ Clin Endocrinol Metab 1997;82:4101-4.

84. Dahia PL, Toledo SP, Mulligan LM, Maher ER, Grossman AB, Eng $C$. Mutation analysis of glial cell line-derived neurotrophic factor (GDNF), a ligand for the RET/GDNF receptor alpha complex, in sporadic phaeochromocytomas. Cancer Res 1997;57:310-3.

85. Duerr EM, Gimm O, Neuberg DS, et al. Differences in allelic distribution of two polymorphisms in the VHL-associated gene CUL2 in pheochromocytoma patients without somatic CUL2 mutations. J Clin Endocrinol Metab 1999;84:320711.

86. Dahia PL, Aguiar RC, Tsanaclis AM, et al. Molecular and immunohistochemical analysis of P53 in phaeochromocytoma. Br J Cancer 1995;72:1211-3.

87. Yoshimoto K, Iwahana H, Fuikuda A, Toshiaki S, Saito S, Itakura $\mathrm{M}$. Role of p53 mutations in endocrine tumorigenesis: mutation detection by polymerase chain reaction-single strand conformation polymorphism. Cancer Res 1992;52:5061-4.

88. Herfarth KK, Wick MR, Marshall HN, Gartner E, Lum S, Moley JF. Absence of TP53 alterations in pheochromocytomas and medullary thyroid carcinomas. Genes Chromosomes Cancer 1997;20:24-9.

89. Reincke $M$, Wachenfeld $C$, Mora $P$, et al. p53 mutations in adrenal tumors: Caucasian patients do not show the exon 4 "hot spot" found in Taiwan. J Clin Endocrinol Metab 1996;81:3636-8.
90. Yana I, Nakamura T, Shin E, et al. Inactivation of p53 is not required for tumorigenesis of medullary carcinoma of thyroid or pheochromocytoma. Jpn J Cancer Res 1992;83:1113-6.

91. Lin SR, Lee YJ, Tsai JH. Mutations of the p53 gene in human functional adrenal neoplasms. J Clin Endocrinol Metab 1994; 78:483-91.

92. Yoshimoto T, Naruse $M$, Zeng $Z$, et al. The relatively high frequency of p53 gene mutations in multiple and malignant phaeochromocytomas. J Endocrinol 1998; 159:24755.

93. Aguiar RC, Dahia PL, Sill H, Toledo SP, Goldman JM, Cross NC. Deletion analysis of the p16 tumor suppressor gene in phaeochromocytomas. Clin Endocrinol (Oxf) 1996;45:93-6.

\section{Endereço para correspondência:}

Patricia Dahia

Dept. Cancer Biology - Dana-Farber Cancer Institute

44 Binney Street SM1010

02115-6084 Boston, MA, USA

Fax: $+1(617)$ 632-4663

e.mail: patricia_dahia@dfci.harvard.edu 